\title{
THE DEVELOPMENT OF SPEECH AND THINKING OF THE STUDENTS WITH HEARING IMPAIRMENTS IN THE SCIENCE CLASS
}

\author{
Sadirova K.G. ${ }^{1}$ \\ Xaydarova O.F. ${ }^{2}$ \\ ${ }^{1,2}$ Teachers of the Department of Deaf Pedagogy, Tashkent State Pedagogical \\ University named after Nizami
}

\begin{abstract}
This article provides specific methods for developing speech and thinking in science lessons, types of speech communication, improving the vocabulary of deaf children in science education, as well as methods for planning speech material for students with hearing disorders.

Keywords: nature, speech, contemplation, perception, defect, dictionary, correction, hearing impaired, sign
\end{abstract} language teaching, deaf child..

\section{INTRODUCTION}

Nature, the events that take place in it, the laws of nature play an important role in the perfect formation of a child's personality. As children become acquainted with these, their mental, moral, physical and scientific worldviews are integrated and formed, and they are brought up in the spirit of nature conservation, care and protection. By teaching science to hearing-impaired children in the natural sciences, it equips them with the knowledge, training, and skills they need to continue their education and practice, shapes their worldview, will, character, develops mental abilities, develops oral speech, increases vocabulary. Based on the fact that students with hearing impairments regularly study the world around them, it forms in them a whole picture of nature, their place and the natural resources of the whole country. To give students a clear knowledge of animate and inanimate nature; teaching them to understand their interdependence; equipping with training and skills to conduct observations in nature; to acquaint with the labor activity of man aimed at the rational use of nature and the preservation of its richness; the goal listed above is the educational goal of teaching science. Deaf and hard of hearing students differ from their healthy peers in the specificity of their thinking and speech development. This uniqueness has an impact on a deaf and hard of hearing child's perception of the world around them. Perceptions of the environment will be limited in relation to a healthy child. Therefore, in the initial period, the level of knowledge is raised with the help of special methods of enrichment, armed with clear ideas. In students with hearing impairment, oral speech is formed as a means of communication from the elementary level. In the early days of education, students learn to accept a teacher's oral speech in two forms, dactyl and oral. The use of hearing aids in education helps students to perceive a teacher's speech through auditory vision. With the main part of the language material used in the process of teaching communication, dactyl speech is also common for oral speech. The main task in teaching oral speech is to form students 'pronunciation skills. Speech is difficult to master by children with hearing impairments. Cognitive processes are formed in the formation of oral speech in children with hearing impairment. In particular, auditory perception, visual perception, tactile-sensory perception are developed. Oral speech is widely used in schools for children with special hearing impairments.

\section{MAIN PART}

All speech material is given by the teacher using oral amplification apparatus followed by oral dactyl without dactyl.

Students with hearing impairments are not given special lessons on speaking at school, but the school curriculum "Speech Development" considers teaching students 5 different types of speech communication:

1. Understand the appeal and execute the order, express the request.

2. Contact the teacher or tutor's assignment partner.

3. Answer the questions.

4. Inform about the work done.

5. Participate in dialogue.

For example, in Grade 1, in the Introduction to the World, the teacher assigns a task using phrases such as "Pour water on a flower," "Give grain to a bird," and the student's ability to complete the task indicates that conversation is developing. The teacher uses dactyl speech in conjunction with oral speech in teaching spoken speech. Dactyl speech is used as an auxiliary means of communication. The teacher gives the student 
the task "Ask a scientist for a bucket" (3rd grade) (Natural sciences, "The importance of people in the spring", practical training). The teacher should be able to use dialogic speech in completing the task. (As a scientist give me a bucket). The teacher can ask the student questions. "What season is it now?", "What kind of animal is a dog?", "Why did it snow?", "Why do the leaves turn yellow?" such as. The ability of a student to describe to a teacher about the work done depends on how well the student has mastered the oral conversation.

"What did you do today?" "Today I planted onions in class" (a junior explains without an oral dactyl). The teacher encourages students to actively participate in the dialogue, to apply the problem situation method correctly. This means that in the process of teaching science to students with hearing impairments, oral, colloquial speech is formed and developed.

One of the most complex forms of speech activity is connected speech, that is, the oral or written presentation of the content of the text read is the main form of connected speech.

An essay is a written creative form of connected speech.

Both of these forms of connected speech are of great importance in the development of speech, the enrichment of speech with literary words, and the development of children's thinking.

Students should be able to answer questions about the basis or observations and events, to expand the answers to the logical side of the answers, to express it in the form of a short story, to distinguish the main aspects of the read, observed and tell them in clear words.

The implementation of this work is based on the following factors.

1. The urges and commands in the context of a connected speech are simple, clear, and related to the specific action part of the person.

2. The urges and commands applied to connected speech allow the formation of an impressive form of speech.

3. Another importance of pronouns is that students remember them quickly because they use specific grammatical categories (noun, verb).

In the teaching of natural sciences, the vocabulary of deaf children is increased and developed. S.A. Zykov, when planning on any subject, the teacher not only determines the content of the lesson, but also distinguishes the speech material in the educational process from the communication between students. For example, in the subject "Natural Science" in the 3rd grade the subject "Animals" is given. The teacher prepared and presented the speech material on the following groups.

\section{Conversational speech selection}

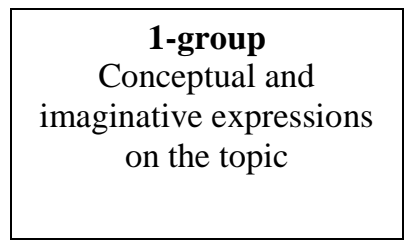

Animals, pets, dogs, horses, cows, cats, cows - give milk, eat grass.

The cat drinks milk.

The dog is a bone marrow transplant. The wool is fluffy, meowing, milky, black and white, gray. similar.

\begin{tabular}{|c|}
\hline 2-group \\
Phrases for teacher-student \\
dialogue \\
\hline
\end{tabular}

Students:

- what do we do.

- Give me a book.

- Give me a white, brown, black pencil.

- Please let me see my case.

- I'm out.

Teacher:

- Ask me a question.

"Scientist, what do you want?"

- Show me.

- Why a pet.

- Tell me.

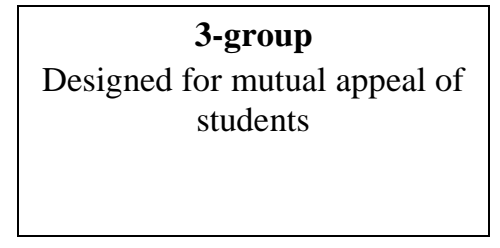

To the duty officer:

- Please fill in the nature calendar.

- Give an observation book. To a friend:

"Do you have a red pencil?"

- like what did you do. - Help me.

- He takes it from me.

Such selection and planning of speech material helps the teacher not only to form concepts and imaginations in children, to develop speech communication. In preparation for the lesson, the teacher also considers the mechanics presented for the speech material.

Thinking and speech play a big, important role in shaping natural ideas and concepts. Often, students Volume 3, Issue VIII, August 2020| 247 
with hearing impairments of small school age are unable to observe nature, draw conclusions, tell the content of their work, find it difficult to connect their observations with practical experience, textbook text, describe the topic studied. Therefore, what is special about speech for use in science lessons is that the teacher uses specific forms of mental work - analysis and synthesis, induction and deduction, to distinguish the most important features, generalize, solve thinking problems, identify cause and effect relationships, compare and contrast you have to rely on putting. Students often have difficulty distinguishing between events, signs of significance of things, so it is necessary to connect this work with observations or based on the imagination of students or based on their memories.

Observations are routinely made on a variety of materials. Observing the flower and its radiance in nature also helps to cultivate curiosity in students, to be able to see and accept the world around them. All this is the basis for the development of thinking and speech.

Speech is primarily divided into internal and external speech. Inner speech is speech that addresses the person himself. It is neither spoken nor written. In internal speech, mainly individual words and phrases are used. Within internal speech, children acquire new knowledge, think about material, and prepare to speak and write: imaginatively speaking, speaking, and then speaking or writing. As a result of such preparation, the quality of students' speech improves. Therefore, the reader encourages children to prepare before speaking or writing, to think about who is speaking before speaking or writing, to choose the right words, to compose sentences.

External speech is speech that is addressed to others. External speech is represented by sounds or graphic symbols. External speech is a two-way activity, implying the presence of narrators and receivers of speech races. The narrator speaks or writes, the receiver reads or hears.

External speech can be dialogic or monologue.

Dialogic, or colloquial speech, involves the exchange of ideas between two or more interlocutors. In the early years of life, children with normal hearing learn their mother tongue on the basis of dialogic speech.

The lexical material, which is mastered by children in the process of learning to communicate, is common to dactyl and oral speech, because all the material in dactyl speech is also necessary for visual and auditory perception of oral speech. But the second aspect of teaching oral speech is also the formation of pronunciation forms in students. The work is done in 2 ways. 1) Dakitil is related to encouraging children to pronounce the speech material orally. These requirements serve to teach students to activate the speech movement apparatus and approach the correct pronunciation of words. 2) Includes systematic work to teach pronunciation. But in this case it remains a means of communication in the formation of speech.

Speech therapy lessons in the school for children with hearing impairments are not included in the syllabus as a special lesson, but are aimed at developing the speech of children with hearing impairments in accordance with the language teaching system and principles of the content of all subjects in primary school.

In grades 1-4, the following requirements are placed on the dialogic form of speech (speech). The program for these classes includes 5 types of communication activities.

1) The child must understand and follow the question, task, assignment, reference asked by the teacher.

2) The student should address the teacher, friends in the form of a dialogue (question, please, willingly).

3) The student should ask a question and answer the question asked by others (on any topic).

4) Provide information about the work done.

5) Everyone should participate in the dialogue on the topic.

All the sentences that constitute oral speech in children with hearing impairments given in the dialogue are mainly communicative content and they meet the following requirement.

1. What is being said is closely and simply connected with human activity and behavior.

2. The content of the speech consists of things and events that occur in the daily life of the child.

3. The development of the child's impressive speech should be accompanied by a careful acceptance of the speech directed at him.

4. Students will remember the given sentences easily and quickly.

The author of the communicative system, S.A. Zykov puts forward the main pedagogical requirements in

"Organization of language teaching for deaf children and the choice of speech material":

Teaching language as a means of communication, that is, when using it, in practice, in dialogue:

1. Educating children in the need and willingness to use word tools:

2. Creating a speaking environment and environment and growing its developmental potential.

3. Ensuring children's language acquisition in the context of the development of practical activities as a team:

4. To teach the use of different forms of speech in interaction and communication with the teacher:

5. Application of dactylology from the earliest stages to develop speech communication in children with hearing impairment, use of dactyl speech as an auxiliary tool with the development of pronunciation and writing skills:

6. Selection of speech material in accordance with the requirements of the program, taking into account the capabilities of children: 
7. Approaching the oral material used in communication to the oral vocabulary and syntax, that is, first of all, to give incomplete sentences, sample questions, exhortations, adverbs:

8. The given speech material should not depend on children's pronunciation, the phonetic structure of words:

9. The given speech material is introduced together with the pedagogue, after the pedagogue, by means of independent (sample-based) speaking, the meaning of the word, it is not necessary to show the methods of their construction:

10. Incorporating the same words into different sentences in order to clarify and generalize the meaning of the words.

\section{REFERENCES}

[1] Sultonova D., Nurmuhamedova N. Special methods of teaching science T. 2006 y.

[2] Titova M.F. Study of nature in correctional schools. M .: Vlados. 2003 year

[3] Klepinina Z.A., Titova M.F. Natural science. 3rd grade textbook. M .: Vlados. 2002 year

[4] Titova M.F. Natural science. 3rd grade textbook. M .: Vlados. 2002

[5] Urunova. Z.N. The Role of Modern Pedagogical Technology in the Development of Cognition in Children with Hearing Impairment. International Journal of Progressive Sciences and Technologies (IJPSAT) ISSN: 2509-0119. Vol. 20 No. 2 May 2020, pp. 32-35.

[6] Abdullaeva M.M.The Development of Conditioned Reflex Motor Reactions in Children after Cochlear Implantation. International Journal of Progressive Sciences and Technologies (IJPSAT) ISSN: 2509-0119. Vol. 20 No. 2 May 2020, pp. 01-03.

[7] Pulatova S.M. Features of Diagnosing the Level of Sensory Development of Preschool Children With Hearing Impairment. European Journal of Research and Reflection in Educational Sciences. Vol. 8 No. 5, 2020. ISSN 2056-5852. pp.18-21

[8] Irgashevich, D. A. (2020). Development of national network (tas-ix). ACADEMICIA: An International Multidisciplinary Research Journal, 10(5), 144-151. Article http://dx.doi.org/10.5958/2249-7137.2020.00254.2 